\title{
Editorial. Enfermedad profesional y médicos de familia
}

\author{
Andrés López Romero \\ Grupo Lex Artis. Somamfyc
}

Fernando León Vázquez
Grupo Lex Artis. Somamfyc

M. ${ }^{a}$ Soledad Holgado Catalán

Grupo Lex Artis. Somamfyc

\section{CONCEPTO}

El Texto Refundido de la Ley General de la Seguridad Social (LGSS), en su artículo 116, define la enfermedad profesional como "la contraída a consecuencia del trabajo ejecutado por cuenta ajena en las actividades que se especifican en el cuadro aprobado por las disposiciones de aplicación y desarrollo de esta Ley, y siempre que la enfermedad proceda por la acción de elementos o sustancias que en dicho cuadro se indican para cada enfermedad profesional".

Este concepto se complementa con otro más extenso, como es el de enfermedad del trabajo, que se define como la ocasionada como consecuencia de la exposición, más o menos prolongada, a un riesgo que existe en el ejercicio habitual de una actividad profesional. Esta mayor amplitud del término implica que englobe tanto a las enfermedades profesionales como a las enfermedades relacionadas con el trabajo.

La enfermedad profesional ha estado ligada históricamente a la manera de buscar una reparación de sus efectos sobre la salud del trabajador, y más recientemente en la prevención de su aparición. Su definición data de la Ley de Bases de 1936, y mantiene hoy algunos de los elementos que la caracterizaban ya entonces:

- Su inclusión en una lista cerrada de actividades y sustancias peligrosas.

- La estricta relación de causalidad entre el trabajo o actividad y la enfermedad profesional; o bien la acción de los elementos nocivos y la enfermedad padecida.

La ajeneidad en la relación laboral, esto es, la necesidad de que la lesión o enfermedad estuviera vinculada a un trabajo por cuenta ajena, ha sido superada, y en la actualidad también es posible el reconocimiento de la enfermedad profesional entre los trabajadores del Régimen Especial de Trabajadores Autónomos por cuenta propia, del Régimen Especial Agrario y del Régimen Especial de los Trabajadores del Mar.

El concepto de enfermedad profesional, aún siendo más rígido que el de accidente de trabajo, también encierra los tres elementos característicos:

- trabajo,

- lesión (enfermedad) y

- relación de causalidad.

Los órganos que se pueden ver afectados por la enfermedad profesional son múltiples, especialmente están representados el aparato locomotor (tendinitis, bursitis), respiratorio (asma, tumores pleurales), piel (dermatitis), hígado (hepatitis tóxicas), sistema nervioso (neurotoxicidad, neuropatías periféricas), reproductor, renal, cardiovascular... En cuanto al mecanismo lesional puede ser diverso, siendo los factores de riesgo más característicos:

- Factores Físicos: ruido, temperaturas extremas, radiaciones, vibraciones...

- Factores químicos: plaguicidas, pinturas, disolventes, humos, polvos...

- Factores biológicos: brucelosis, carbunco, tétanos...

- Factores ergonómicos: manipulación de cargas, movimientos repetidos, posturas forzadas... 
Las enfermedades que producen los diferentes agentes, no difieren esencialmente de otras patologías cuyo origen es extralaboral; por lo que si no pensamos en ellas, pasaremos por alto su etiología laboral y su abordaje específico. Tal es el caso de la hipoacusia de percepción, el síndrome de Raynaud, lesiones cutáneas, cataratas, asma, hepatopatias, lumbalgias, entesopatías, bursitis, tenosinovitis, neuropatías por atrapamiento, etc.

El diagnóstico de una enfermedad profesional se basa en una presunción legal surgida de un doble listado de actividad y enfermedad. Así, si la enfermedad está en el listado y quien la padece desarrolla una actividad con riesgo de adquirir dicha enfermedad, hay una presunción iuris et de iure (no admite prueba en contrario) de que es profesional, por lo que no se impone la prueba de la relación de causalidad a diferencia de la enfermedad del trabajo, donde sí es necesaria dicha prueba. Para reconocer el origen profesional de una patología es necesario la concurrencia de tres condiciones:

- que la enfermedad esté incluida en el cuadro de enfermedades profesionales,

- que el trabajador/a esté o haya estado expuesto a uno de los agentes causantes del cuadro,

- que el trabajador desempeñe una actividad recogida en el cuadro.

El establecimiento de listas de enfermedades profesionales expresa la voluntad de restringir el reconocimiento de ellas a las que cumplen con determinadas condiciones que, a priori, han sido evaluadas para ese efecto. Con ello, se garantiza la concesión automática de las prestaciones para aquellas que aparecen en la lista, al reconocerse el origen de profesional a un caso de enfermedad. En España, la regulación se establece por el Real Decreto 1299/2006 de 10 de noviembre, por el que se aprueba el cuadro de enfermedades profesionales en el sistema de la Seguridad Social y se establecen los criterios para su notificación y registro, y se completa con la Orden TAS 1/2007, de 2 de enero por la que se establece el modelo de parte de enfermedad profesional, se dictan normas para su elaboración y transmisión y se crea el correspondiente fichero de datos personales.

Este Real Decreto recoge un anexo I donde se incluyen aquellas enfermedades cuyo origen profesional se ha reconocido científicamente, y un anexo II de enfermedades cuyo origen y carácter profesional podrían establecerse en un futuro. La adopción en España del sistema de doble listado propuesto por la Recomendación Europea 2003/670/CEE supone un avance en el registro y la notificación de enfermedades profesionales y de daños a la salud causados por actividades laborales.

\section{PRESTACIONES}

Las prestaciones económicas y sanitarias derivadas de una enfermedad profesional son:

- Prestaciones por Incapacidad Temporal (IT)

- Prestaciones por Lesiones Permanentes no Invalidantes

- Prestaciones por Incapacidad Permanente

- Prestaciones por Muerte y Supervivencia

- Prestaciones Recuperadora y de Readaptación Profesional (tratamiento sanitario, orientación profesional, formación profesional).

El contenido de la prestación sanitaria incluye:

- Asistencia médica encaminada a la reparación íntegra del daño causado

- Asistencia farmacéutica totalmente gratuita

- Prestaciones complementarias totalmente gratuitas

- Prestaciones ortopédicas

- Transporte sanitario

La otra prestación más relevante es el subsidio, que se abonará desde el día siguiente al de la baja en el trabajo, siendo su cuantía el $75 \%$ de la base reguladora, y estando a cargo del empresario el salario íntegro correspondiente al día de la baja. 
La enfermedad profesional tiene, frente al accidente de trabajo, peculiaridades y características propias en la acción protectora de la Seguridad Social, que conlleva diferencias preventivas (reconocimientos médicos, cambio de puesto de trabajo) y diferencias técnicas (período de observación, particularidades en la incapacidad, muerte y supervivencia).

\section{Reconocimientos médicos}

Todas las empresas que deban cubrir puestos de trabajo con riesgo de enfermedad profesional, están obligadas a practicar, a su cargo, reconocimientos médicos previos a la admisión de quienes vayan a ocuparlos, así como a realizar los reconocimientos periódicos que para cada tipo de enfermedad se establezcan en las normas (art. 196 y 197 del LGSS). Estos reconocimientos son obligatorios y gratuitos para los trabajadores. Las empresas no podrán contratar trabajadores que no hubieran sido declarados aptos en el reconocimiento o permitir la continuación en su puesto de trabajo en el caso de que esta inaptitud fuera descubierta en los reconocimientos periódicos. El incumplimiento de estas obligaciones por parte de la empresa, la convierte en responsable directa de todas las prestaciones económicas que pueden derivarse en tales casos de enfermedad profesional.

\section{Cambio de puesto de trabajo}

Entre las medidas protectoras especiales en relación con la enfermedad profesional se incluyen los traslados de puesto de trabajo (art. 45 de la OM de 9 de mayo de 1962). En caso de que no sea posible el cambio de puesto de trabajo se establecen una serie de medidas que se remontan a los años sesenta y cuya vigencia actual no está clara, por lo que no se suelen aplicar. En los casos en los que, como consecuencia de un reconocimiento médico se descubra algún síntoma de enfermedad profesional que no constituya IT, pero cuya progresión sea posible evitar mediante el traslado del enfermo a otro puesto de trabajo exento de riesgo, se deberá llevar a cabo dicho traslado dentro de la misma empresa, sin que este cambio afecte a las retribuciones que venía percibiendo el trabajador (artículo 133.2 del LGSS). Los médicos que, en el ejercicio de sus funciones, descubran dicha situación, informarán a la empresa de si el cambio tiene carácter provisional o definitivo, debiéndolo hacer también a la Autoridad laboral y a la entidad con la que esté concertado el seguro de accidentes de trabajo y enfermedades profesionales. Si no hay posibilidad de traslado, el trabajador debe ser dado de baja en la empresa, previa conformidad de la Inspección de Trabajo, e inscrito con carácter preferente para ser empleado por la Oficina de Empleo. Mientras no esté ocupado, el trabajador tiene derecho a percibir un subsidio equivalente a su salario íntegro.

\section{Periodo de observación}

Se considera período de observación el tiempo necesario para el estudio médico y determinación del agente causante de la enfermedad profesional, cuando hay necesidad de aplazar, para poder asegurar, el diagnóstico de la misma (artículo 133 LGSS; artículo 128 1.b del LGSS). Durante este periodo, pueden darse dos supuestos: que el trabajador pueda continuar con la realización de su trabajo, o que se prescriba la necesidad de su baja laboral. En este último supuesto, el propio LGSS determina que, a todos los efectos, el periodo de observación tiene la consideración de situación legal de IT.

Los periodos de observación tendrán una duración máxima de seis meses prorrogables por otros seis, cuando se estime necesario para el estudio y determinación del diagnóstico. La competencia para conceder esta prórroga corresponde al INSS conforme a lo dispuesto en el artículo 1.1 c del RD 1300/1995. Al término del periodo de observación, el trabajador pasará a la situación que proceda de acuerdo con su estado. Esta situación podrá consistir en curación, paso a situación de IT o calificación del grado de incapacidad que proceda.

\section{Incapacidad, muerte y supervivencia}

En relación con la muerte y supervivencia, prácticamente en nada se diferencian de la ocasionada por accidente de trabajo. Sin embargo, en caso de enfermedad profesional, se admite en todo momento la prueba de que la muerte deriva de dicha situación, sin que exista aquí el límite de cinco años previsto para los accidentes de trabajo. Hay medidas protectoras específicas para silicosis (artículo 45 de la OM de 9 de mayo de 1962, modificada por la de 30 de abril de 1977). 


\section{NOTIFICACIÓN DE UNA ENFERMEDAD PROFESIONAL}

En la Orden TAS 1/2007, de 2 de enero, se establece el modelo de parte de enfermedad profesional, se dictan normas para su elaboración y transmisión y se crea el correspondiente fichero de datos personales. El nuevo parte de enfermedad profesional pretende cumplir con el objetivo de la Unión Europea en cuanto al aprovisionamiento de una serie coherente de datos, lo que conlleva recoger aquella información que Eurostat considera necesaria en el orden a las tareas de armonización estadística, además de facilitar el seguimiento de la salud y la seguridad en el trabajo y la eficacia de la reglamentación en este ámbito, contribuyendo a la prevención de los riesgos laborales.

Los médicos de familia o cualquier otro facultativo del Sistema Público de Salud que, con ocasión de sus actuaciones profesionales, tengan conocimiento de la existencia de una enfermedad profesional lo comunicarán a la Mutua y/o al INSS; de igual modo lo harán los facultativos de los Servicios de Prevención.

La entidad gestora o la mutua que asuma la protección de las contingencias profesionales está obligada a elaborar y tramitar el parte de enfermedad profesional, tanto si se produce baja como no, sin perjuicio del deber de las empresas o de los trabajadores por cuenta propia que dispongan de cobertura por contingencias profesionales, de facilitar a aquélla la información que obre en su poder y les sea requerida para la elaboración de dicho parte.

La cumplimentación y transmisión del parte de enfermedad profesional se realiza únicamente por vía electrónica, por medio de la aplicación informática CEPROSS (Comunicación de Enfermedades Profesionales de la Seguridad Social), a la que se accede a través de la oficina virtual de la dirección electrónica www.seg-social.es. La comunicación inicial del parte ha de llevarse a cabo dentro de los diez días hábiles siguientes a la fecha en que se haya producido el diagnóstico de la enfermedad profesional y, en los cinco días hábiles siguientes a la comunicación inicial se tienen que cumplimentar todos los datos a partir de la información facilitada por la empresa. A la información contenida en el sistema CEPROSS pueden acceder, a efectos del desarrollo de sus respectivas competencias en esta materia, la Administración de la Seguridad Social, la Administración Laboral y la Inspección de Trabajo y Seguridad Social en los términos establecidos en el artículo 21 de la Ley Orgánica 15/1999, de 13 de diciembre, de Protección de Datos de carácter personal. Las restantes administraciones, instituciones, organizaciones y entidades afectadas por razón de la materia podrán disponer de la información de carácter estadístico que resulte necesaria para el cumplimiento de sus fines.

\section{EL PAPEL DEL MÉDICO DE FAMILIA}

La gestión de las enfermedades profesionales puede ser asumida por una Mutua o por el INSS, quienes determinarán si es una enfermedad profesional o no. Sin embargo la calificación de las enfermedades profesionales corresponde en última instancia al INSS (RD 1299/2006, art. 3). El papel del médico de familia es fundamental a la hora de reconocer y derivar a estos organismos a los trabajadores con sospecha de estas patologías.

Muchas de las enfermedades profesionales se presentan como enfermedades comunes o como síntomas inespecíficos, es la etiología lo que hace sospechar que sean laborales o no. La mayoría de las personas con una patología laboral acuden inicialmente a médicos no especializados en Medicina del Trabajo, muy a menudo a su Médico de Familia. Si no se realiza una historia de exposición laboral y/o medioambiental, es poco probable que se haga un diagnóstico etiológico. Al no detectar la exposición responsable de la sintomatología, dicha exposición puede persistir e incluso el tratamiento puede ser incorrecto.

Una adecuada historia clínica laboral debe recoger como mínimo la ocupación, profesión o tarea desarrollada, el número de años en el puesto, la descripción de la jornada laboral tipo. Además deberá recoger las exposiciones laborales actuales y previas (materiales productos, ambientes...), la presencia de otros trabajadores con sintomatología o exposición similar, las medidas y utilización de equipos de protección, y la evolución temporal de la sintomatología.

La importante variabilidad biológica de los individuos hacer que no todos los trabajadores expuestos a un mismo riesgo o a una condición patógena similar enferman y los que enferman, no lo hacen al mismo tiempo y con la misma intensidad. También ocurre que un mismo agente puede presentar efectos nocivos 
diferentes según las condiciones de exposición y en función de la vía de entrada al organismo. A ello se une la multicausalidad de las enfermedades, con diferentes factores laborales y extralaborales implicados que actúan simultáneamente y que contribuyen al desencadenamiento de la misma. La mayoría de enfermedades profesionales no tienen un cuadro clínico específico que permita relacionar la sintomatología con un trabajo determinado.

El cometido el médico de familia es:

- SOSPECHAR la patología de origen laboral

- INDAGAR sobre las tareas desarrolladas por el trabajador enfermo

- Estudiar, diagnosticar, tratar y DERIVAR en su caso adecuadamente al trabajador

- PROPONER a la Inspección la Determinación de Contingencias en su caso

- INFORMAR al paciente sobre su enfermedad, la normativo aque la rige y las peculiaridades de la misma

\section{- CONSULTAR con la Inspección Médica}

La Sociedad Española de Medicina Familiar y Comunitaria ha propuesto algunas medidas para mejorar la gestión de la Enfermedad Profesional en atención primaria. Mejorar la formación de los profesionales, simplificar el proceso burocrático que supone la gestión de la incapacidad temporal por enfermedad profesional, poder contar con un consultor experto en salud laboral, o la posibilidad de disponer de una unidad de gestión de demoras diagnósticas son algunas de ellas.

Un mejor conocimiento y una mayor sensibilización de los médicos de familia con las enfermedades profesionales se traduciría en beneficios para el Sistema de protección de la Seguridad Social y sobre todo en beneficios para el paciente-trabajador enfermo. 